\title{
Spectrometric gamma radiation of shale cores applied to sweet spot discrimination in Eastern Pomerania, Poland
}

\author{
Rafal Skupio $^{1}$ - Gabriel de Alemar Barberes ${ }^{2}$
}

Received: 27 December 2016/ Accepted: 10 October 2017/Published online: 23 October 2017

(c) The Author(s) 2017. This article is an open access publication

\begin{abstract}
This paper describes the application and calculation of hydrocarbon anomalies in two different boreholes located in Eastern Pomerania (northern Poland). Spectrometric data from borehole geophysical probe (borehole 1) and portable gamma logger (borehole 2) were used to analyze shale formations. The results from borehole 1 presented a statistically significant, moderate correlation between calculated hydrocarbon anomalies and hydrocarbon saturation data obtained from well log interpretation. Borehole 2 has been analyzed focusing on the gamma radiation of the core samples, and the positive results of borehole 1. Hydrocarbon anomalies calculated from spectral gamma radiation are reliable indicators of sweet spots, based solely on a cursory evaluation of core measurements. These preliminary information acquired from gamma-ray measurements could help increase sampling precision of further geochemical analysis.
\end{abstract}

Keywords Gamma radiation - Hydrocarbon anomalies . Eastern Pomerania $\cdot$ Shales $\cdot$ Well logging

Rafal Skupio

skupio@inig.pl

1 Oil and Gas Institute - National Research Institute, Lubicz 25 A, 31-503, Kraków, Poland

2 Geosciences Gentre \& CITEUC - Department of Earth Science and Center of Geoscience, Faculty of Science and Technology, University of Coimbra, Coimbra, Portugal

\section{Introduction}

Well logging is a fundamental method of formation evaluation. There are many techniques and tools that allow for measurements of physical properties of the rock matrix and pore media (Ellis and Singer 2007). The results can be used to determine lithology, shale volume, mineral composition, porosity, and water/hydrocarbon saturation (Dresser 1982). Data obtained from well logs is always influenced by well conditions, and thus laboratory measurements performed on cuttings or core samples are required for all oilfields. Non-destructive core samples measurements, such as spectral natural gamma-ray intensity, bulk density and computed tomography (CT) provide the possibility of performing continuous logging with laboratory precision (Ashi 1995). In the current study, gamma radiation methods were used to acquire a database for thorium normalization calculations and analysis.

Gamma radiation is a product of nuclear decay and is characterized by a spectrum whose shape corresponds to the characteristic energies of the individual isotopes. Identifying the energies of these isotopes allows for the matching of the radioactive elements present in the examined material (Lisieski 1967; Skupio 2015). Geologists use many types of spectrometers to indicate radiation emanating from rock layers, such as handheld spectrometers to measure outcrops, gamma loggers adopted to measure drilling cores (Skupio 2015), geophysical tools to use in boreholes and airborne gamma spectrometer or satellites to measure radiation across whole districts (Kulisek et al. 2015).

The first thorium normalization method for hydrocarbon exploration was introduced by Saunders et al. (1993) and concerned only surface and aerial measurements. The methodology was also applied in active exploration oil 
fields in 6 American states, 2 Australian basins and the Wadi Araba Desert in Egypt (El-Sadek 2002; Al-Alfy et al. 2013). Barberes et al. (2014) applied thorium normalization (TN) and hydrocarbon anomalies (HA) in shales from the South Portuguese Zone to determine areas with possible hydrocarbon emanations to characterise an unconventional petroleum system. Al-Alfy (2009), who first applied thorium normalization method to well logging, concluded that his results mostly agree with the interpretation of hydrocarbon saturation in Lower Miocene in Egypt. In 2013, Al-Alfy et al. (2013) continued his work on conventional oilfields in different areas in Egypt to locate the oil-bearing zones using only the gamma-ray spectroscopy data.

The purpose of this study is to show the application of thorium normalization on well logging data and core measurements for shale deposits located in the northern Poland. Data from B1 (borehole 1) contains a set of geophysical measurements and involves petrophysical interpretation with hydrocarbon saturation and lithology; which were further used to correlate the results with hydrocarbon occurrence. Data from B2 (borehole2) includes only spectral gamma measurements on cores that had been measured by the gamma logger device with a BGO (Bismuth Germanate) detector. In addition, this data allows for depth matching of the cores with well $\operatorname{logs}$, which is crucial for comparing laboratory analyses with the holistic interpretation of well logs.

\section{Geological framework and localisation}

Eastern Pomerania is located northern part of Poland and is bordered by the Baltic Sea. The whole area (onshore and offshore) is located within the contact area between two great geological units separated by the Teisseyre-Tornquist Tectonic Zone (TTZ). The TTZ goes through all of Poland from NW to SE, the width of zone ranging from 20 to $100 \mathrm{~km}$ (Antonowicz et al. 1994). TTZ divides the Pomerania region into Western Pomerania, located on the Palaeozoic platform, and Eastern Pomerania located on the Precambrian platform. In regional geological literature, the area located east from the TTZ called the Peribaltic Synclise because it refers to preserved lower Palaeozoic deposits that presently form a extremely large syncline, which could be considered a product of the Baltic Basin evolution (Karnkowski et al. 2010). The Baltic Basin is divided by two separate depocentres. One is the NE-SW trending Baltic Depression in the central and eastern part of the basin, and the other is the Peri-Tornquist zone in the western part, adjacent to the TTZ (Poprawa et al. 1999).

This study presents wireline data collected from boreholes situated in the northern Poland in the Eastern
Pomerania district. The approximate location of the two wells is indicated by the red dots on the map (Fig. 1). The distance between the boreholes is about $40 \mathrm{~km}$. Almost the entire Eastern Pomeranian region was covered by exploration contracts for shale gas potential in 2015 .

The general stratigraphic and lithological profiles of the boreholes (examined part) are represented by Silurian and Ordovician formations. Data from B1 reaches up to the Upper Cambrian. The Silurian stratigraphy in B1 contains the Pridoli, Ludlow, Wenlock and Llandovery epochs, where the lithological profile consists mostly of shales with limestone interbeds (about $28 \mathrm{~m}$ of Silurian limestones), siltstones, anhydrites and marls. Ordovician period is represented mostly by shales, conglomerates, marls (about $7 \mathrm{~m}$ ) and limestones (about $10 \mathrm{~m}$ ). Upper Cambrian is mostly constituted of laminated shales and limestones. The examined profile of B2 is much shorter and contains about $40 \mathrm{~m}$ of Silurian laminated shales (from the Llandovery epoch) and about $20 \mathrm{~m}$ of Ordovician shales and marls.

\section{Methods and techniques}

Spectrometric data for the calculation of hydrocarbon anomalies was collected by gamma logger and well logging tools. These spectrometers are based on scintillation detectors, which allow for the measuring of characteristic energy emitted by radioactive elements such as potassium $\left({ }^{40} \mathrm{~K}\right)$, uranium $\left({ }^{238} \mathrm{U}\right)$ and thorium $\left({ }^{232} \mathrm{Th}\right)$. The resulting measurements for these methods ought to give similar effect despite different environmental conditions and positioning of the detector. Radiometric measurements are always affected by background noise. There are many sources, but the most common are: cosmic radiation, radiation from building materials, impurities in the crystal of the detector, contamination in the measurement system and the measurement method itself (Blum et al. 1997).

\section{Spectral gamma ray logging-results in borehole 1 (shared data)}

The spectral gamma ray tool (SGR) was used to investigate geological layers in B1. The SGR tool has a commonly used detector consisting of a scintillation counter built from a sodium iodide crystal doped with a thallium impurity $\mathrm{NaI}(\mathrm{Tl})$ and a photo-multiplier tube (PMT) (Ellis and Singer 2007). The crystal, typically $5 \mathrm{~cm}$ in diameter and $20 \mathrm{~cm}$ long, has much greater volume than in the simple gamma ray tool, it gives the tool better sensitivity (Rider 2000). Data acquired by the SGR tool is not affected by background noise, like in the case of laboratory 
Fig. 1 Approximate locations of the two wells in the examined district are indicated with red dots. The map presents the Pomeranian region in northern Poland. The dashed line represents the boundary of the Polish Exclusive Economic Zone of the Baltic Sea. B1borehole 1, B2-borehole 2 (Adapted from Karnkowski et al. 2010)

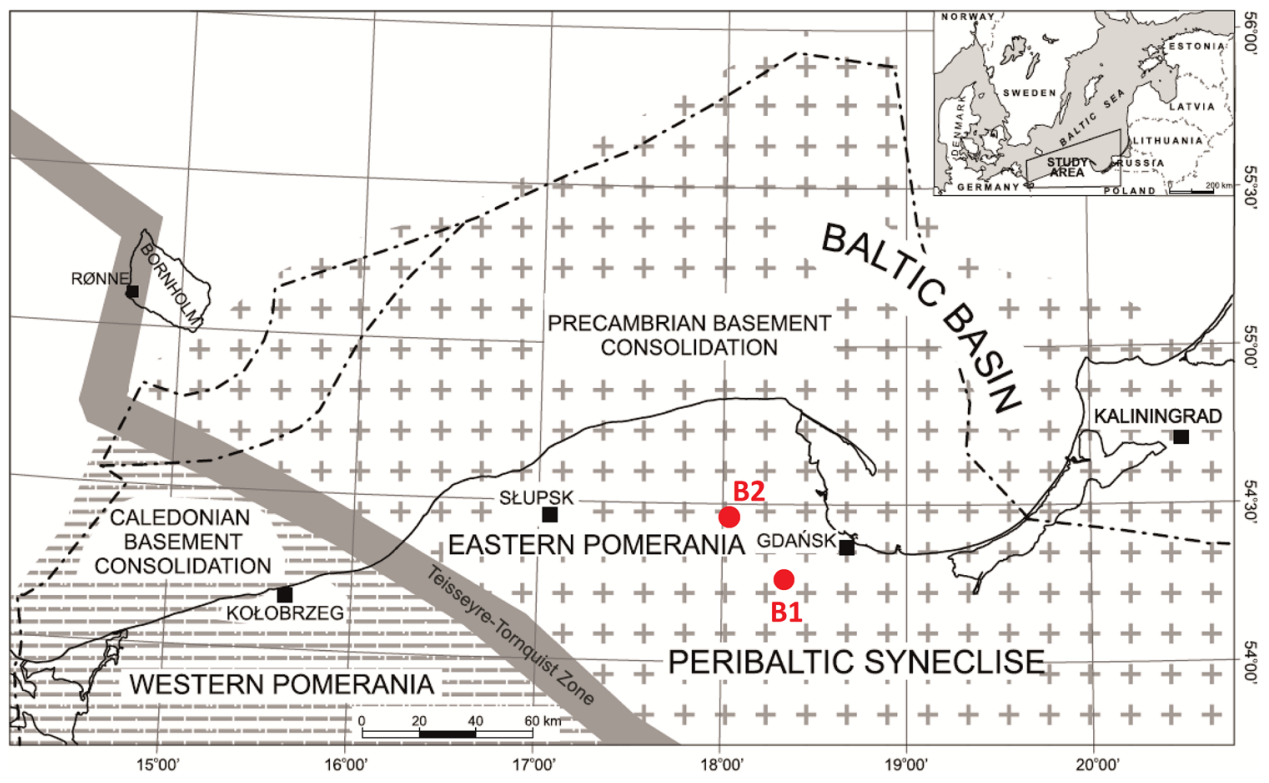

Spectral gamma-ray core measurements-results in borehole 2 (acquired data)

The gamma logger device (Fig. 2) adapted to $1 \mathrm{~m}$ core samples was used to measure cores from B2.

The device was built using a 2 inch BGO detector $\left(\mathrm{Bi}_{4} \mathrm{Ge}_{3} \mathrm{O}_{12}\right)$ because of the high atomic number of bismuth leads to its high density, and allows the detector to achieve a very high efficiency (Skupio and Dohnalik 2015). BGO detectors are on average $10 \%$ more efficient for radioactive particle detection than $\mathrm{NaI}(\mathrm{Tl})$ detectors of the same size (Knoll 2000; Van der Graaf et al. 2007). This better efficiency allows for a reduction of the measurement time (Hendriks et al. 2001), which is normally set for 1 min per point in the case of shale cores (n.b. rock with low activity requires much longer time of acquisition) and its smaller size compared to SGR allows for the increase of the vertical resolution. A drawback of $\mathrm{BGO}$ detectors is their poorer spectrum resolution: $10-15 \%$ for ${ }^{137} \mathrm{Cs} 662 \mathrm{keV}$
Fig. 2 Gamma logger spectrometer made by Kirk Petrophysics adapted to core measurements. Detector (1) is built with two inch BGO crystal with electronics placed in lead shield (2), this unit moves linearly over a given core (3) at a specified interval. Device is plugged into a computer (4) which enables immediate downloading and quality control of the data

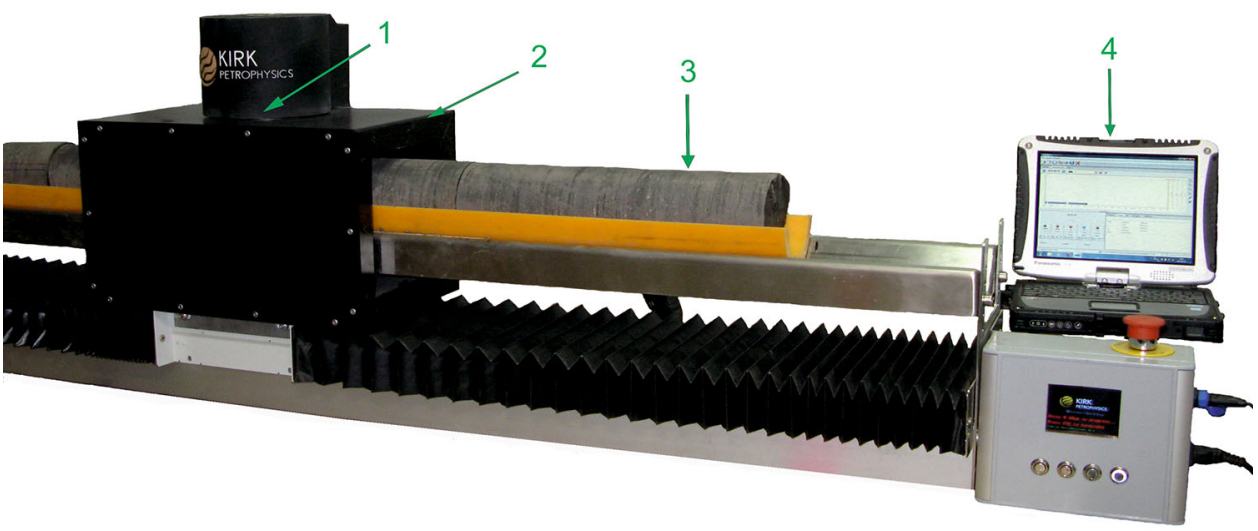


gamma rays (Bakkum et al. 1984); BGO is only about half as good as that which can be obtained with $\mathrm{NaI}(\mathrm{Tl})$ detectors (L'Annunziata 2012). However, in the case of K, $\mathrm{U}$ and $\mathrm{Th}$, there is no need for high spectral resolution. On the spectrum registered by the BGO there are three main characteristic peaks, which are flatter than those from the $\mathrm{NaI}$ spectrum, but they have more counts per window, which gives better statistical results during the computation process. To reach a proper assessment of radioactive elements, two sets of calibration standards with 10 and $8 \mathrm{~cm}$ diameters (Fig. 3), were used to calibrate the device. It is important to note that the calibration must be run on site to account for local BG noise. The uncertainty of measurement was established for $\mathrm{K}$ by running 7, $1 \mathrm{~min}$ analyses on the $\mathrm{K}$ calibration standard. The uranium and thorium uncertainty was derived from that of $\mathrm{K}$. The results are as follows: for potassium is $0.25 \%$; for uranium is $1.4 \mathrm{ppm}$ and for thorium is $2.8 \mathrm{ppm}$.

Spectrometric data acquired from clean drilling core is not influenced by borehole effects, which is a big advantage (because corrections are not needed). Unfortunately, the surrounding radiation of the environment is high. Because of that, the location of measurement is important. To minimize background noise, the scintillation detector and measured material are shielded by $5 \mathrm{~cm}$ of lead. During measurements on shale cores, the placement of the machine is not crucial because of the strong signal from the formations. When measurements are being carried out on rocks of low radiation it is recommended to select a location with lower background radioactivity or apply better shielding.

Spectrometric data from B2 was acquired in the core repository with set of $0.1 \mathrm{~m}$ step and 1 min time of measurements. The spectrometer was located on a table about

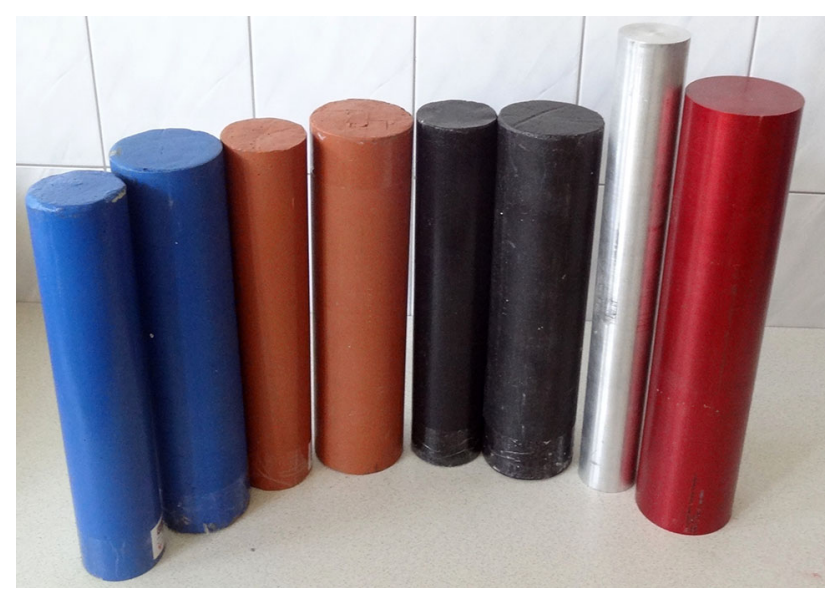

Fig. 3 Set of calibration cylinder standards $(8,10 \mathrm{~cm}$ diameters $)$ used to calibrate the gamma logger. Blue-uranium (U), redthorium (Th), black-potassium (K), silver and light red-inactive (aluminum) used to measure local background
$1 \mathrm{~m}$ above the ground to avoid overestimation of the background noise. RSAnalyst software, designed by Georadis s.r.o, imports data to the database and allows for checking spectra and the level of radiation. Spectrometric data downloaded directly from the device is not calibrated with the standards. The device calibrates itself on the basis of background radiation level, but results are not real values of radiation in the cores. The real concentrations of elements are computed, with additional module in the RSAnalyst software which needs measured etalons spectra activity information, ROI range (Region of interest-range of energy windows on the spectrum), and spectra of core measurements. The software uses the least square method to compute the most probable contents of $\mathrm{K}, \mathrm{U}$ and $\mathrm{Th}$. It compares the shape of spectra from core measurements at set ROI range, to the shape of etalons spectra at that same range (Bartosek 1977).

The measured part of B2 core interval was $62 \mathrm{~m}$ in length. The results include only three logs with information about: $\mathrm{K}[\%], \mathrm{U}$ [ppm] and $\mathrm{Th}$ [ppm]. Total radiation can be read from direct measurement in [cps] or [ppm] but is not relevant for this study. To verify the accuracy of the measurement and computation process, additional laboratory measurements on the available core material were made. Eleven points of interval have been chosen to perform laboratory tests with the use of MAZAR spectrometer (Kowalska et al. 2010). Samples were chosen after spectrometric gamma radiation measurements which were performed on the whole core. It helped with more accurate selection from layers characterized by diverse levels of radiation. Core material before laboratory measurement was crushed and split to obtain accurate results from a smaller part of the core $(150 \mathrm{~g})$.

\section{Method of computing hydrocarbon anomalies}

To identify radiometric anomalies related to hydrocarbon occurrence, it is necessary to develop a model to explain such anomalies. One of most successful models was developed by Saunders et al. (1993). A basic assumption is that whatever changes the apparent concentration of thorium also affects the concentration of uranium and potassium in similar, predictable ways. If hydrocarbons are not present, ${ }^{238} \mathrm{U},{ }^{40} \mathrm{~K}$ and ${ }^{232} \mathrm{Th}$ should be in natural and constant proportions (Saunders et al. 1993).

Over the years, researchers have applied thorium-normalization (TN) and hydrocarbon anomaly (HA) as an auxiliary method for hydrocarbon exploration, and also to minimise exploration risk, therefore, increasing the success rate of potential areas. The characteristics and fluctuations of the DRAD (the mathematical expression of hydrocarbons anomalies, defined by Saunders et al. 1993) values in non-oil and gas producing areas can be estimated by 


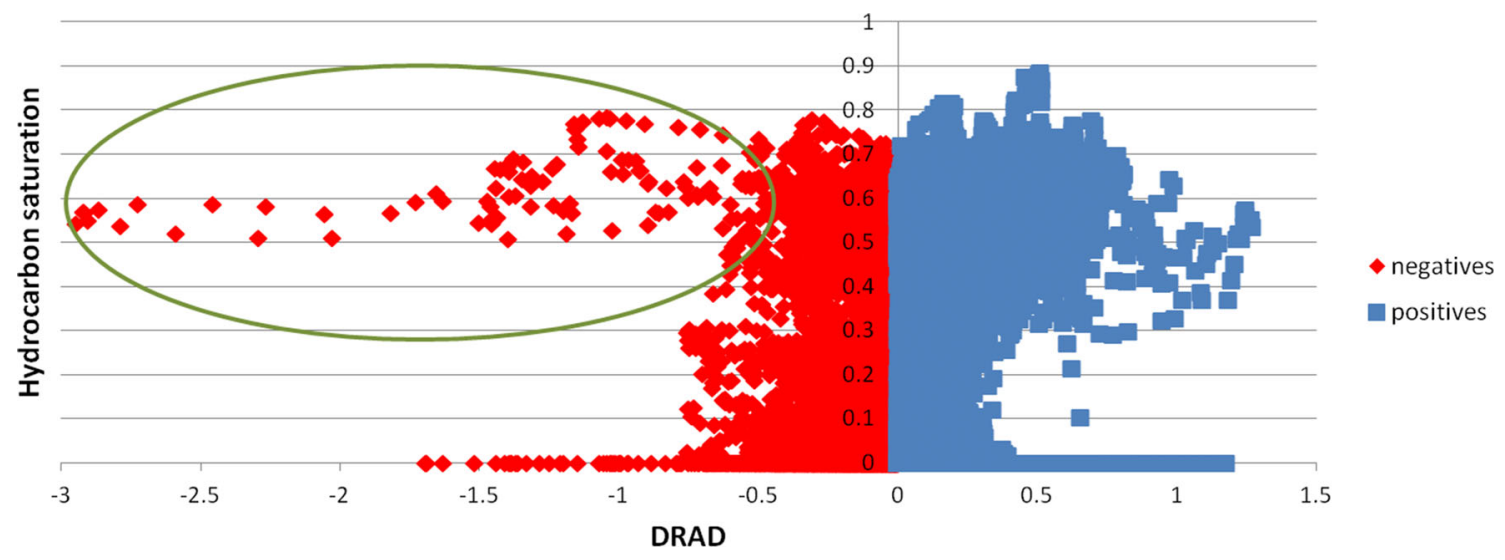

Fig. 4 DRAD and hydrocarbon saturation graph. DRAD is presented on the $X$ axis and hydrocarbon saturation is presented on the $Y$ axis. The green ellipse marks the anomalous values of negative DRAD, related to carbonatic levels

Table 1 Sum of DRAD values frequencies in every interval of hydrocarbon saturation

\begin{tabular}{llll}
\hline HS & Neg. [\%] & Pos. [\%] & Total [\%] \\
\hline 0 & 70.7 & 29.3 & 100 \\
0.1 & 66.1 & 33.9 & 100 \\
0.2 & 58.8 & 41.2 & 100 \\
0.3 & 70.8 & 29.2 & 100 \\
0.4 & 60.7 & 39.3 & 100 \\
0.5 & 43.3 & 56.7 & 100 \\
0.6 & 37.2 & 62.8 & 100 \\
0.7 & 32.4 & 67.6 & 100 \\
0.8 & 29.4 & 70.6 & 100 \\
0.9 & 0 & 100 & 100 \\
\hline
\end{tabular}

analysing of these profiles in the studied area. The application of these criteria along the flight line lead to the identification of an area with valid anomalies, possibly indicating an accumulation of exploitable hydrocarbons (El-Sadek 2002).

Based on detailed studies of radiometric measurements in oilfields, Saunders et al. (1993) developed a relationship between ${ }^{238} \mathrm{U},{ }^{40} \mathrm{~K}$ and ${ }^{232} \mathrm{Th}$ data in order to help identify HA. ${ }^{40} \mathrm{~K}$ concentrations appear to be significantly lower over oil and gas fields, and ${ }^{238} \mathrm{U}$ was found to be slightly concentrated in profiles over Alabama Ferry, Leona, O.S.R., and Lonesome Dove Fields, Texas (Saunders et al. 1993; Prost 2014). ${ }^{232} \mathrm{Th}$ is considered to be highly immobile in rocks and local soils, it is not affected by the hydrocarbon ascension. Based on these assumptions, Saunders et al. (1993) defined the "ideal" ${ }^{40} \mathrm{~K}$ and ${ }^{238} \mathrm{U}$ as:

$\mathrm{K}_{i}=\left(\mathrm{K}_{\mathrm{av}} / \mathrm{Th}_{\mathrm{av}}\right) \times \mathrm{Th}_{s}$

$\mathrm{U}_{i}=\left(\mathrm{U}_{\mathrm{av}} / \mathrm{Th}_{\mathrm{av}}\right) \times \mathrm{Th}_{s}$

where the subscript "s" refers to the measured or sampled value, " $\mathrm{i}$ " is the ideal value and "av" is the average value of the studied area (surface of several $\mathrm{km}^{2}$ or length of particular well interval). The normalized difference between the measured values and the ideal values is then calculated (Saunders et al. 1993):

$\mathrm{KD}=\left(\mathrm{K}_{s}-\mathrm{K}_{i}\right) / \mathrm{K}_{s}$

$\mathrm{UD}=\left(\mathrm{U}_{s}-\mathrm{U}_{i}\right) / \mathrm{U}_{s}$

In hydrocarbon presence, KD should decrease and UD generally increases. To capitalise upon these two relationships, Saunders et al. (1993) defined a new parameter, known as DRAD:

$\mathrm{DRAD}=\mathrm{UD}-\mathrm{KD}$

Therefore, HA are normally characterised by positive values of DRAD and negative values of $\mathrm{KD}$ and UD (Saunders et al. 1993).

The technique described above was used to determine oil bearing zones and sandstone reservoirs in different Egypt areas. Al-Alfy applied DRAD methodology for subsurface gamma ray spectrometry logs and showed agreement between calculated results and well log analyses in three studied oil fields (Al-Alfy 2009; Al-Alfy et al. 2013). Based on this works it is possible to introduce this method for core analysis field. Nowadays there is no other technique enables for continuous core measurements with hydrocarbon zones discrimination.

\section{Results and discussion}

For this work about $1600 \mathrm{~m}$ interval from B1 were used to make DRAD calculations, it crosses the Silurian, Ordovician and Cambrian formations. The results of $\mathrm{B} 1$ revealed a moderate, direct correlation $(R=0.4)$ between hydrocarbon occurrence (hydrocarbon saturation) and the values of DRAD (hydrocarbon anomaly). Statistical analysis showed 


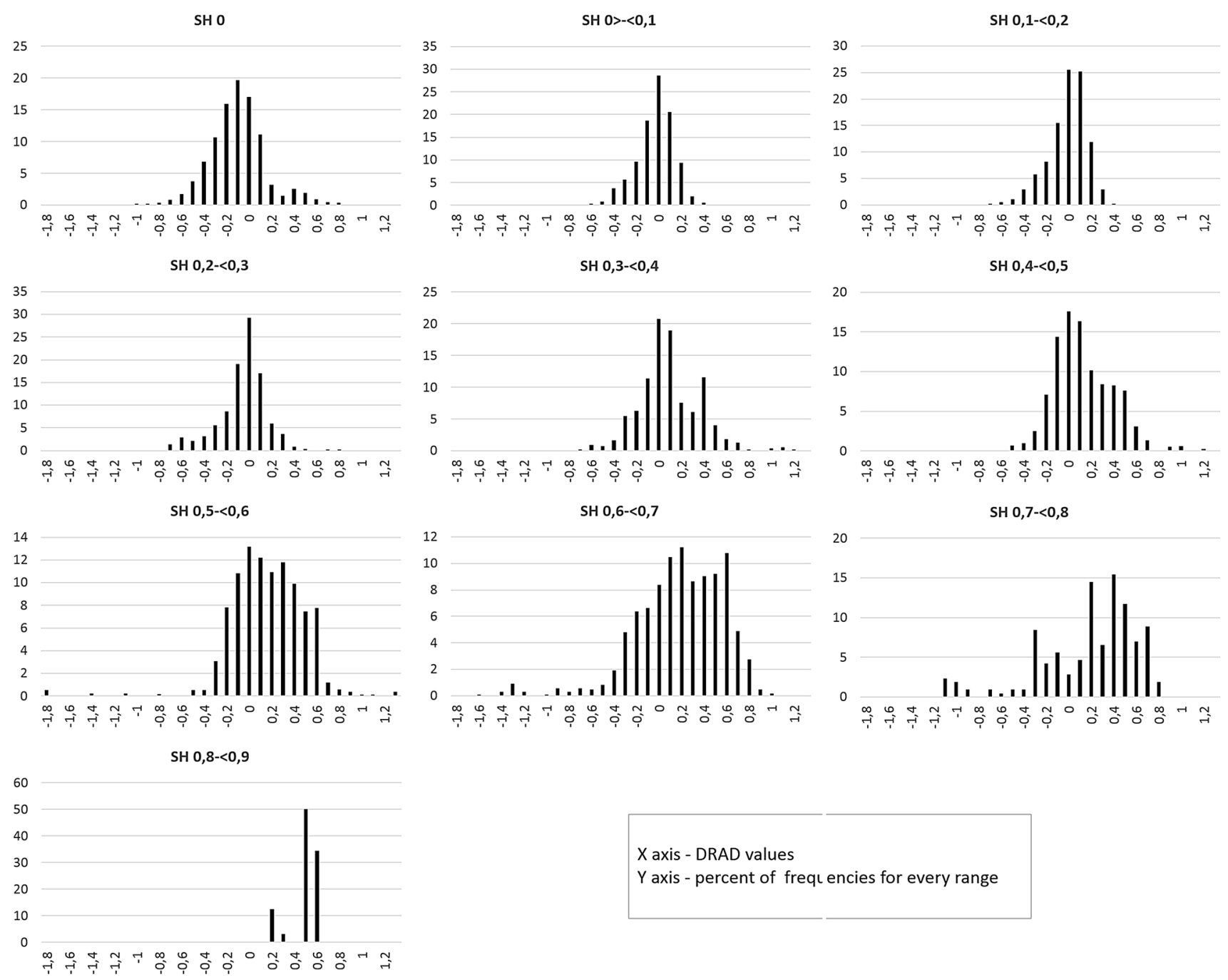

Fig. 5 Set of histograms with DRAD values for each hydrocarbon saturation interval. There is a clear statistically significant correlation between the increase of hydrocarbon saturation and increase of DRAD values

that this result is statistically significant at $\alpha=0.01$ for 19,048 samples $(p<\alpha)$. In Fig. 4. DRAD is presented in $X$ axis and hydrocarbon saturation is presented in $Y$ axis. The green ellipse on the graph indicates the anomalous negative DRAD values, in general related to carbonatic levels (about $40 \mathrm{~m}$ thick).

Calculated results show changes which are analyzed with the use of a set of histograms for clearer data visualization. Based on the Fig. 4 database, it is possible to make histograms using the relative frequencies of DRAD values for every $\mathrm{SH}$ interval, which are summarized in Table 1. Analyzing this table, there is a strong correlation between HS and \% of negative and positive values, $R^{2}=0.87$.

The graphical composition of DRAD values for each hydrocarbon saturation range, is presented in Fig. 5. The graph shows, for $\mathrm{SH}=0$, the negative values represent the highest frequencies and they decrease with higher SH. For positives values, $\mathrm{SH}=0$ represents the lowest frequencies. With increasing hydrocarbon saturation, the DRAD values increase and become more frequent.

These results from well B1 are a good argument for applying the DRAD calculation method to indicate hydrocarbon anomaly intervals. This method was applied to field work performed on the core from well B2 (data without SH curve). The results are shown in Fig. 6 containing $\mathrm{K}, \mathrm{U}$ and $\mathrm{Th}$ curves, with measurements from eleven samples on laboratory equipment (Table 2) and DRAD values. The whole composition shows intervals with a greater probability of hydrocarbon anomaly occurence (i.e. the positives). Based on these results, it is possible to indicate potentially interesting well intervals and core sections that could be tested further in the laboratory. Spectrometric gamma radiation measurements performed on crushed samples (MAZAR equipment), and confirmed 


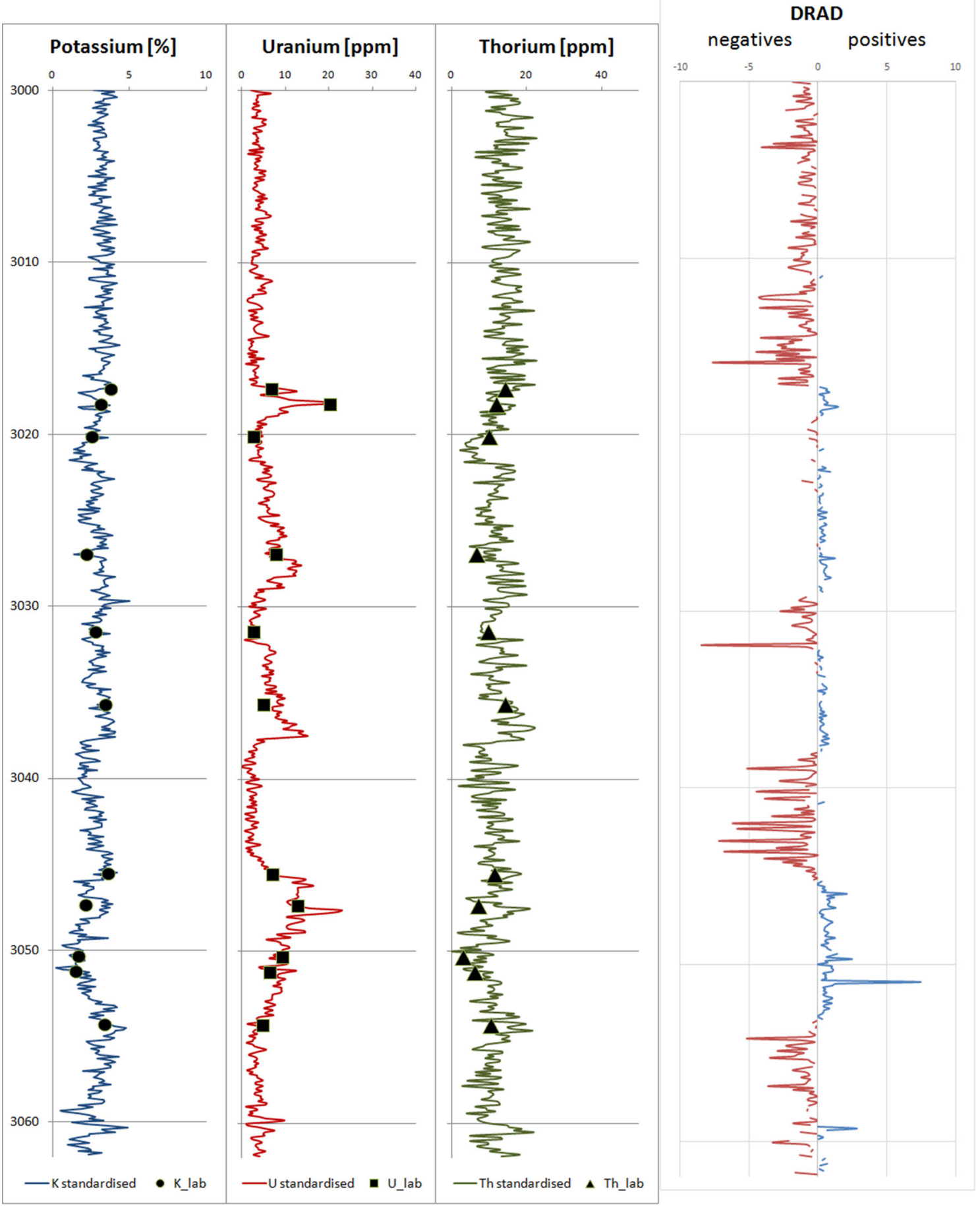

Fig. 6 Spectrometric gamma logging with laboratory measurements and DRAD values calculated from the shale core-B2. The red curve represents negatives values of DRAD and blue curve represents positives values of DRAD

the precision of the fast field work core measurement with the use of the Gamma Logger (BGO).

Spectrometric gamma measurements provide simple uranium content which can be used to quickly determine intervals with higher possibility of hydrocarbon presence in shales. Because results calculated for borehole B1 show the correlation between SH and DRAD to be higher $(R=0.4$, $p<0.01)$ than that of SH and $\mathrm{U}(R=-0.1, p<0.01)$, it is more effective in predicting levels with hydrocarbons accumulations. For the statistical analysis of the whole of B1 (19,048 samples) Pearson's correlation coefficient (PC) was calculated using IBM SPSS software (Mudelsee 2003). 
Table 2 Gamma spectrometric results from laboratory measurements performed on eleven samples indicated on the B2 spectrometric logs (Fig. 6)

\begin{tabular}{llcc}
\hline Depth [m] & K [\%] & U [ppm] & Th [ppm] \\
\hline 3017 & 3.75 & 6.64 & 14.19 \\
3018 & 3.09 & 20.05 & 11.84 \\
3020 & 2.50 & 2.54 & 9.88 \\
3027 & 2.16 & 7.73 & 6.66 \\
3031 & 2.78 & 2.58 & 9.67 \\
3036 & 3.42 & 4.77 & 14.23 \\
3045 & 3.60 & 6.92 & 11.44 \\
3047 & 2.11 & 12.55 & 6.96 \\
3050 & 1.62 & 9.14 & 2.84 \\
3051 & 1.44 & 6.31 & 6.18 \\
3054 & 3.37 & 4.70 & 10.39 \\
\hline
\end{tabular}

Our results show that the thorium normalization method may be applied as an additional factor for sweet spot discrimination in Silurian and Ordovician shales. Earlier studies by Saunders et al. (1993), El-Sadek (2002) and AlAlfy et al. (2013) have applied this method in active exploration oil fields, matching positive anomalies in $70-80 \%$ of the actual producing fields. According to Saunders et al. (1993), the spectral data covers portions of six American states, showing ${ }^{40} \mathrm{~K}$ and ${ }^{238} \mathrm{U}$ anomalies, in at least $72.7 \%$ of the 706 gas and oil fields. Tests were also performed in two Australian basins, showing a correlation between the radiometrically favourable areas and the known oil and gas producing regions. According to ElSadek (2002), the three variables $\left({ }^{238} \mathrm{U},{ }^{232} \mathrm{Th}\right.$ and $\left.{ }^{40} \mathrm{~K}\right)$ in the NE area of the Wadi Araba Desert (Egypt) were scanned every kilometer, along flight paths. The Aguarita and Dark Horse oil fields and Selden gas field in Texas, were discovered using gamma ray spectral data in conjunction with soil gas sampling, magnetic susceptibility measurements, and subsurface geology (Prost 2014).

Saunders et al. (1993) showed that thorium normalization (TN) for the spectral gamma-ray data of ${ }^{238} \mathrm{U}$ and ${ }^{40} \mathrm{~K}$ effectively supress the lithological and environmental effects of both surface and aerial radiometric data. This allows for the measurement of detailed factors related to hydrocarbon presence in depth. Al-Alfy et al. (2013) applied the same method to several oil fields in Egypt to determine the hydrocarbon behaviour in sandy reservoirs. The results from this method match those from the three studied areas (Suez Gulf, offshore of Nile Delta and South Valley), with agreements of 82,78 and $71 \%$, respectively. From the high levels of agreement between the TN method and the results from well analysis, the calculated DRAD curve can be used as an indicator of oil accumulations in different wells (Al-Alfy et al. 2013).

\section{Conclusions}

The results from B1 confirm that thorium normalization method (DRAD parameter) can be an easy and rapid way to indicate hydrocarbon saturated intervals in the borehole profile, before well log interpretation. This technique can support early stages of exploration, indicating levels of hydrocarbons with higher occurrency. Data acquired from gamma logger surveys (core measurements-B2) allow for the prediction of $\mathrm{SH}$ occurrence. It is the fastest way to make measurements directly after a coring procedure and indicate significant intervals only with spectral gamma core data.

These studies show that the DRAD calculation method is applicable to deep buried shales occurring in the Eastern Pomerania region. It is possible to use this calculation method for both wireline and core measurements. The correlation of $\mathrm{SH}$ with uranium content and $\mathrm{SH}$ with DRAD values show that this method is more effective than simple uranium curve control for rapid determination of hydrocarbon anomalies.

Acknowledgements This work was supported by The National Centre for Research and Development in the framework of the BLUE GAS-POLISH SHALE GAS project BG1/MWSSSG/13. The data from wireline logging and interpretation results was shared by Polish Oil and Gas Company (PGNiG) for the Blue Gas project (BG1/ MWSSSG/13). This work was also supported by FEDER funds through the Competitiveness Factors Operational ProgrammeCOMPETE, and national funds by FCT in the framework of the UID/ Multi00073/2013 and UID/Multi/00611/2013 projects. The authors are very grateful to $\mathrm{CNPq}$ (Brazil), Statoil (Brazil) and PGNiG (Poland).

Open Access This article is distributed under the terms of the Creative Commons Attribution 4.0 International License (http://crea tivecommons.org/licenses/by/4.0/), which permits unrestricted use, distribution, and reproduction in any medium, provided you give appropriate credit to the original author(s) and the source, provide a link to the Creative Commons license, and indicate if changes were made.

\section{References}

Al-Alfy IM (2009) Radioactivity and reservoir characteristics of lower Miocene rocks in Belayim marine oil field. Ph.D. Thesis, Faculty of Science, Zagazig University, Zagazig, Egypt, p 174

Al-Alfy IM, Nabih MA, Eysa EA (2013) Gamma ray spectrometry logs as a hydrocarbon indicator for clastic reservoir rocks in Egypt. Appl Radiat Isot 73:90-95

Antonowicz L, Iwanowska E, Rendak A (1994) Tensional tectonics in the Pomeranian section of the T-T Zone and the implications for hydrocarbon exploration. Geol Quart 38(2):289-306

Ashi J (1995) CT scan analysis of sediments from Leg 146. In: Carson B,Westbrook GK, Musgrave RJ, Suess E (Eds) Proceedings of the Ocean Drilling Program Scientific Results, vol 146 (Pt. 1). College Station, TX (Ocean Drilling Program), p 191-199 
Bakkum EA, Van Engelen CPM, Kamermans R, Teeling TA, Timmerman LJM (1984) The response of BGO scintillation detectors to light charged particles. Nucl Instrum Methods Phys Res 225:330-334

Barberes GA, Pena dos Reis R, Fonseca PE, Pimentel N, Azevedo M (2014) Application of Thorium-Normalized method to identify any hydrocarbons anomalies in South Portuguese Zone Carboniferous units. Comun Geol 101(2):743-746

Bartosek J (1977) Citliva metoda stanoveni obsahu prirozene radioaktivnich prvku v horninach. Kandidatska disertacni prace. Geofizika Brno

Blum P, Rabaute A, Gaudon P, Allan JF (1997) Analysis of natural gamma-ray spectra obtained from sediment cores with the shipboard scintillation detector of the ocean drilling program: example from leg 1561. In: Shipley TH, Ogawa Y, Blum P, Bahr JM (Eds). Proceedings of the Ocean Drilling Program, Scientific Results, $\mathrm{p} 156$

Dresser A (1982) Well logging and interpretation techniques: the course for home study, 3rd edn.

Ellis DV, Singer JM (2007) Well logging for Earth Scientists, 2nd edn. Springer, Berlin

El-Sadek MA (2002) Application of thorium-normalized airborne radio-spectrometric survey data of Wadi Araba area, Northeastern Desert, Egypt, as a guide to the recognition of probable subsurface petroleum accumulations. Appl Radiat Isot 57:121-130

Hendriks PHGM, Limburg J, de Meijer RJ (2001) Full-spectrum analysis of natural $\mathrm{g}$-ray spectra. $\mathrm{J}$ Environ Radioact 53:365-380

Karnkowski PH, Pikulski L, Wolnowski T (2010) Petroleum geology of the Polish part of the Baltic region-an overview. Geol Quart 54(2): $143-158$

Knoll Glenn F (2000) Radiation detection and measurement, 3rd edn. Wiley, New York

Kowalska S, Lewandowska A, Buniak A (2010) Reasons of the anomalous indications of the gamma ray $\operatorname{logs}$ for the Lower
Permian rocks from the Wolsztyn High area. Nafta-Gaz $6: 425-440$

Kulisek JA, Schweppe JE, Stave SC, Bernacki BE, Jordan DV, Stewart TN, Seifert CE, Kernan WJ (2015) Real-time airborne gamma-ray background estimation using NASVD with MLE and radiation transport for calibration. Nuclear Instrum Methods Phys Res Sect A Accel Spectrom Detect Assoc Equip 784:287-292

L'Annunziata MF (2012) Handbook of radioactivity analysis, 3rd edn. Elsevier Inc., USA

Lisieski W (1967) Praktyczna spektrometria promieniowania gamma w badaniach technicznych. Nowa technika zeszyt 70, Wydawnictwa Naukowo-Techniczne, Warszawa

Mudelsee M (2003) Estimating Pearson's correlation coefficient with bootstrap confidence interval from serially dependent time series. Math Geol 35(6):651-665

Poprawa P, Sliaupa S, Stephenson R, Lazauskiene J (1999) Late Vendian-Early Paleozoic tectonic evolution of the Baltic Basin: regional tectonic implications from subsidence analysis. Tectophysics 314:219-239

Prost GL (2014) Remote sensing for geoscientists-image analysis and integration. CRC Press, New York

Rider M (2000) The geological interpretation of well logs, 2nd edn. Whittles Publishing, Dunbeath

Saunders DF, Burson KR, Branch JF, Thompson CK (1993) Relation of thorium-normalized surface and aerial radiometric data to subsurface petroleum accumulations. Geophysics 58:1417-1427

Skupio R (2015) Accuracy assessment of the determination of radioactive elements concentration on shale cores. Nafta-Gaz 6:390-399

Skupio R, Dohnalik M (2015) Improvement spectrometric gamma measurements on shale cores with the use of the BGO scintillation detector. Nafta-Gaz 11:847-855

Van der Graaf ER, Rigollet C, Maleka PP, Jones DG (2007) Testing and assessment of large BGO detector for beach monitoring of radioactive particles. Nuclear Instrum Methods Phys Res A 575:507-518 